\title{
Stage IIA Distal Bile Duct Cancer AJCC v8
}

National Cancer Institute

\section{Source}

National Cancer Institute. Stage IIA Distal Bile Duct Cancer A/CC v8. NCI Thesaurus. Code C134815.

Stage IIA includes: (T1, N1, M0); (T2, N0, M0). T1: T umor invading the bile duct wall with a depth less than $5 \mathrm{~mm}$. T2: Tumor invading the bile duct wall with a depth of 5-12 mm. N0: No regional lymph node metastasis. N1: Metastasis in one to three regional lymph nodes. M0: No distant metastasis. (AJCC 8th ed.) 